\title{
Outdoor Educators' Influence on the Self-Growth Process of Participants: A Case Study of Educators at the Buddy Kids Adventure Challenge Program
}

\author{
Hiroya Endo', Kenryu Aoyagi1,2, Koichiro Oka ${ }^{3}$ \\ ${ }^{1}$ Waseda Institute for Sport Sciences, Waseda University, Tokyo, Japan \\ ${ }^{2}$ College of Economics, Kanto Gakuin University, Yokohama, Japan \\ ${ }^{3}$ Faculty of Sport Sciences, Waseda University, Tokyo, Japan \\ Email: hiroya.endomame@gmail.com
}

How to cite this paper: Endo, H., Aoyagi, K., \& Oka, K. (2017). Outdoor Educators' Influence on the Self-Growth Process of Participants: A Case Study of Educators at the Buddy Kids Adventure Challenge Program. Advances in Physical Education, 7, 332-342. https://doi.org/10.4236/ape.2017.73027

Received: July 18, 2017

Accepted: August 15, 2017

Published: August 18, 2017

Copyright $\odot 2017$ by authors and Scientific Research Publishing Inc. This work is licensed under the Creative Commons Attribution International License (CC BY 4.0).

http://creativecommons.org/licenses/by/4.0/

\begin{abstract}
The nature experience is important for the growth of children. However, the opportunities of children's nature experience are decreasing today because of a lack of various programs and right outdoor educator. To resolve these issues, providing valuable outdoor educators' training is important, although there are few studies about outdoor educators in Japan and the influence of outdoor educators' intervention on participants has not been clarified. In order to consider more effective educators' learning contents, it is necessary to understand actually how the involvement of the educators influences the growth of the children. Therefore, the purpose of the present study was to explore the influence of educators' intervention in outdoor activity programs on children's growth. Our study included interviews for 12 educators of the Buddy Kids Adventure Challenge Program (BKACP). The data obtained through semi-structured interviews was analyzed using Modified Grounded Theory Approach (MGTA). The analysis resulted in the generation of 69 concepts and 31 categories demonstrated. This analysis revealed the influence of outdoor educators' intervention on participants. The overall process was confirmed that outdoor educators' intervention made the participants rely on one's own feeling, which promoted self-growth of participants who had deep experiences. In conclusion, the intervention of skilled outdoor educators who know rules of nature guarantees the children's independence in a highly flexible program, and furthermore, it is thought that positive emotions (known as flow) on overcoming adversity promote self-growth. It would be attractive for outdoor educators to use flow theory as a learning tool.
\end{abstract}

\section{Keywords}

Flow Theory, Outdoor Educators, Self-Growth, M-GTA 


\section{Introduction}

Experiential activity in Japan was promoted to cultivate a zest for living among the youth, as specified in "About the Way of Education of Japan in 21 Century, First Edition" (Ministry of Education, Culture, Sports, Science and TechnologyJapan, 1996). According to a survey conducted by the Ministry of Education, there is a positive relationship between nature experience and the formation of self during childhood. Because of this, it is important to create social systems that promote nature experiential activities for the youth. However, today's youth seldom has the opportunity for nature experiences (National Institution for Youth Education, 2006, 2010, 2011). At the Enhancement of Outdoor education for Young People meet (Research and Collaborators Meeting and Report on Promotion of Outdoor Education for Young People, 1996), it was pointed out that "The existence of educators is essential for outdoor education. Also, it is needless to say that the quality and quantity of educators influence the success of outdoor educational programs". According to the report titled "Towards the development of autonomous youth who will be responsible for the next generation" (Ministry of Education, Culture, Sports, Science and Technology-Japan, 2013), "educational resources such as appropriate educators and activity program are not sufficient", and "it is necessary to supply high quality experience and skillful educators for youth". This means that there is a lack of resources like appropriate leaders, educators, and activity programs, which lead to a lack of essential leadership and high-quality experiences for the youth. According to Hijikata (2008, 2013), there are few studies regarding outdoor educators, even though the teachings and values behind nature experiences of veteran educators are important. Noguchi and Murayama (1995) pointed out that the importance of educators lies not only in their teaching various skills, but also in their handing down of their own ideas and spirit. However, these studies have not focused on the effects of the educators' influence on the youth. Therefore, the research question of the present study is "What is the best way to provide guidance in terms of the type of educators and program offered?" The aim of this study is to clarify how outdoor educators in the BKACP influence the self-growth of children, by using the M-GTA. According to Endo et al. (2015), the distinctive features of BKACP are activities that are "long-term", "cover a lot of activity types", and are held in "real nature". This program nurtures self-respect and morality, and facilitates deeply emotional experiences, which are important for a child's growth. Since outdoor educators are the drivers of these experiences and influence them, it is appropriate to consider them the subjects of this present research.

\section{Methods}

\subsection{Subjects}

Twelve educators who led the BKACP in 2014 (organized by the non-profit organization Buddy Adventure Group) were interviewed. According to Guest et al. 
(2006), approximately $90 \%$ of potential opinions are extracted by interviews with 12 members therefore twelve respondents were chosen. The respondents' level of experience, the number of years they have participated in the program, and their specialized activities are shown in Table 1.

\subsection{Survey Procedure}

One-on-one semi-structured interviews were conducted with all respondents. The interview guide for the educators was based on the results of another interview that three of the educators gave. The interview included questions on the "evaluation of the program", "effects of the program", "ideas for outdoor education", “important teaching points", and "educators' problems", as well as openended questions in accordance with the conversation to clarify the influence of intervention of the outdoor educators.

The outdoor educators were interviewed at Buddy Adventure Group's office by the first author for a duration of 40 minutes to 60 minutes. Participants were told the purpose and contents of the interview, that it was voluntary, and that all personal information would remain confidential. They were then asked to sign papers proving their official consent. Consent was obtained from the Ethics Committee on Research Involving Human Subjects at Waseda University (2014-236) as well. The investigation period was from March to May 2015.

\subsection{Analysis}

The present study focuses on the outdoor educators' point of view and aims to clarify their influence on the self-growth of children. To this end, M-GTA was adopted to create and categorize concepts, because according to Kinoshita (2010), this approach is the most appropriate for studies whose target phenomena have features of processing. The theme is "to determine the contents and processes of

Table 1. Features of the subject.

\begin{tabular}{cccccc}
\hline No. & Age & Sex & Experience (years) & Favorite activity event & $\begin{array}{c}\text { Qualification and } \\
\text { performance }\end{array}$ \\
\hline 1 & 35 & Female & 9 & Kayaking & National tournament \\
2 & 35 & Female & 7 & Surfing & National tournament \\
3 & 19 & Male & 2 & Skiing & - \\
4 & 35 & Male & 10 & Life guard & Life guard instructor \\
5 & 57 & Male & 25 & Mountaineering & Mountain guide \\
6 & 38 & Female & 9 & Surfing & Basic life guard \\
7 & 35 & Female & 6 & Lifesaving & Basic life guard \\
8 & 58 & Male & 30 & Mountaineering & Mountain guide \\
9 & 45 & Male & 25 & Surfing & Advance instructor \\
10 & 44 & Male & 8 & Running & National tournament \\
11 & 32 & Female & 8 & Lifesaving & Lifesaving instructor \\
12 & 49 & Male & 30 & Skiing & - \\
\hline & & & & & \\
\hline
\end{tabular}


the educators' influence on the participants", and the objects of analysis are "the educators". Concepts were created in the analysis worksheet, which compared the "analysis theme" to "the educators". After considering the relationship among the generated concepts, categories were created to summarize their relationship in the analysis results. This analysis was carried out by three researchers; the first researcher made the analysis worksheet (title, explain, data example, consideration) and in case of the contents which are complicated to analyze, discussed with the second researcher, while the third researcher supervised.

\section{Results}

Sixty-nine concepts and thirty-one categories were created by repeatedly encoding and sorting 137 interview transcripts. Note that in this manuscript, brackets (i.e., [ ]) indicate categories, while underlined words indicate concepts. Figure 1 shows the effects of outdoor educators' intervention on the self-growth of the participants. There is a stream from [The influence of outdoor educators] to [Self-growth]. Participants can [Rely on ones' own sense or feeling] owing to [The influence of outdoor educators], and within [Program design] and Profound emotional experience, the ideas of [Being emotionally moved] and [Adversity] promote [Self-growth]. In particular, overcoming [Adversity] allows participants to obtain a Sense of achievement from a Successful experience related to Selfconfidence, which promotes [Self-growth]. In addition, there is also a [Sense of achievement], Sense of Achievement while overcoming adversity, and Sense of achievement after giving it your all. The former is similar to the state of mind of [Flow], which is the Fun in Concentration. The [Flow] works as a motivating power to enhance the desire of [Mastery] or [Motivation] intrinsically and continually, and helps promote [Self-growth]. The most important aspect within this process is [Adversity], which contains the concepts Overcoming fear, So fun we forget the fatigue, and Scary but fun, which means participants not only overcame pain or difficulty, but also had fun. This aspect is influenced by the fact that outdoor educators consider the [Definition of adversity] as to not give participants too much stress, as well as the concepts of Sense of achievement isn't everything, Adversity is not the goal, and There are also failed experiences, which are all included in [Program design]. In addition, in order to obtain [Selfgrowth], it is necessary to have [Buddy magic], which is a category that includes the concepts Comfort, The strength of Fellowship, Chance of growth in non-interference, and Being watched warmly. [Realization of growth], which includes Mental toughness, Pro-social behavior, Leadership, and Assessment of the situation, are [The features of the participants]. Also, the [Ability to react to nature], which includes Familiarity with nature and Understanding of the Law of nature, as well as the concepts Desire for activities and Leading to quality of Life] contribute to the cultivation of body. Participants cultivate their own body in each program, which relates to the [Readiness] to [Rely on one's own senses or feeling].

\section{Discussion}

The present study attempted to create a self-growth process model using a qua- 


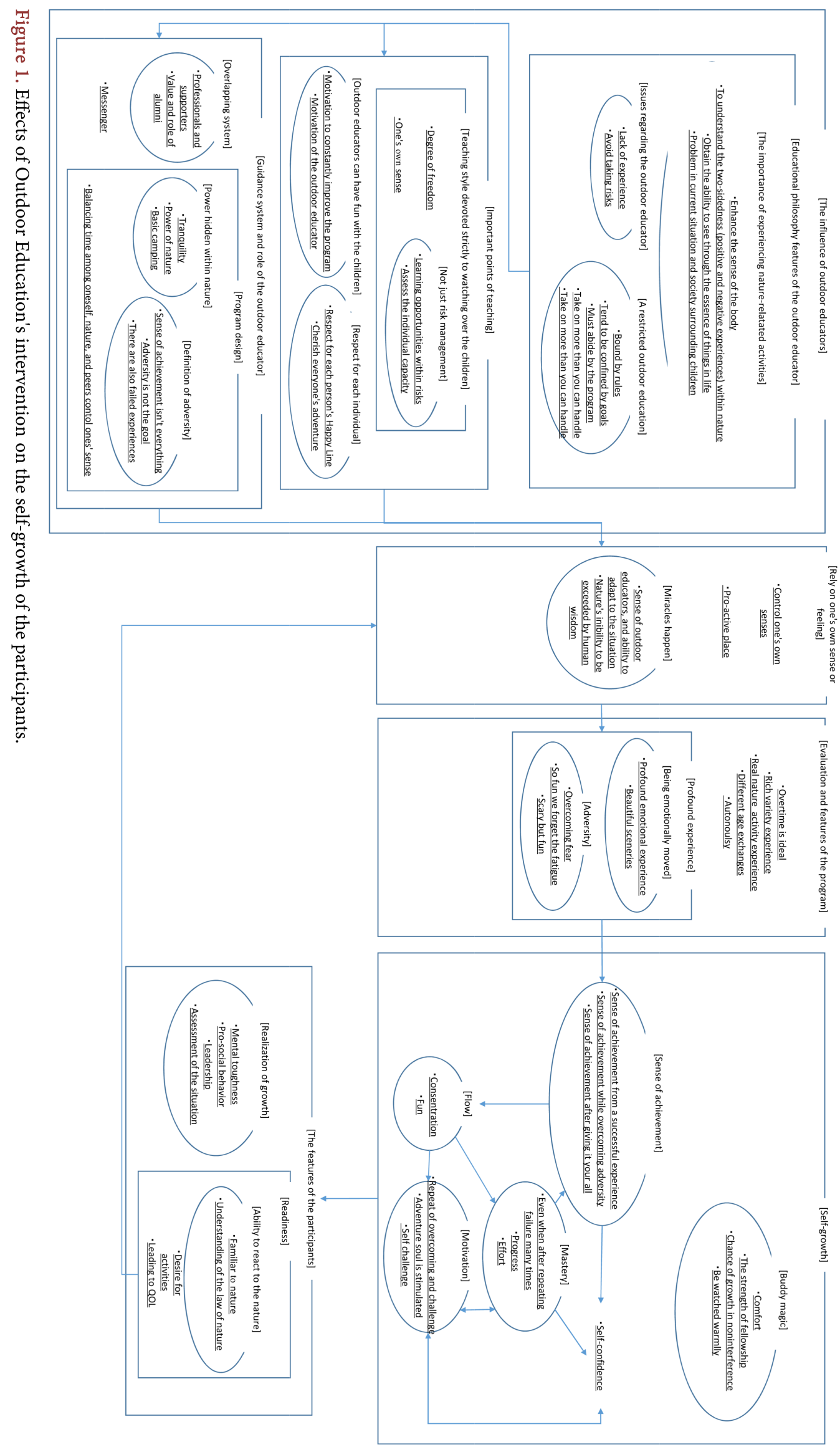


litative study method, to clarify the influence of outdoor educators' intervention on participants' self-growth.

Noguchi and Murayama (1995) state that it is important that outdoor educators not only teach but also communicate ideas, ideals, and the philosophy of outdoor education through their activities. For these reasons, this research first compiled the respondents' philosophy of outdoor education. It then studied how the respondents' philosophy of outdoor education affected their teaching methods.

[Educational philosophy of the outdoor educators] includes the categories [The importance of nature-related activities], [Issues regarding the outdoor educator], and [A restricted outdoor education]. [The importance of nature-related activities] is to enable participants to acquire natural providence by honing their internal body sensations. [Issues regarding the outdoor educator] is to have a few experiences but not take risks. [A restricted outdoor education] is to be bound by rules, to get caught up with the goal, or to feel overloaded by the contents of the program.

It was found that the respondents' philosophy of outdoor education influences [Important point of teaching] and [Guidance system and role of the outdoor educator]. What is important is the Degree of freedom in the program. Habata and Suzuki (2010) pointed out the importance of "free play". Free play is important because during this time, it is possible for one to adjust the challenge level in which one can demonstrate their abilities. Onno (2012) states that it is important to not simply look at everything as dangerous, but to allow children to face challenges in order to play freely in nature. Onno also points out that the presence of professional lifeguards is indispensable, and the biggest factor, in the safe practice of these programs. The outdoor educators of this study were qualified and experienced; therefore, we believe that [Teaching style devoted strictly to watching over the children], in which appropriate risk management and Degree of freedom go together, was realized.

In [Guidance system and role of outdoor educators], [Program design] is important. [Power hidden within nature]-which includes the concepts of Tranquility, Power of nature, and Basic camping-and [Definition of adversity] are included in [Program design]. In nature and camping, richness of the experience of the outdoor educators is important in order to utilize the power of the "place" (Hijikata, 2008).

The outdoor educators of this study, from their own experience, have concrete explanations for Tranquility, Power of nature, and Basic camping, as follows. Tranquility means that in nature, especially when there is nobody around, it is easier for the educators to create their own world and to increase the subjective understanding of the participants. Tranquility is not artificial, but it is a world other than ourselves and nature, so that one can take decisions based on their own intentions and judgment.

Power of nature means that it is possible to greatly impact the participants by feeling the energy of nature in all of one's sensory organs. Basic camping means 
that the essence of living will be visible by living outdoors, with the minimum necessary tools. The reason the outdoor educators of this research can explain a way to draw concrete [Power hidden within nature] is because their own experiences are rich. [Definition of adversity] includes the concepts of Sense of achievement is not everything, Adversity is not the goal, and There are also failed experiences. Camping and activities in nature can result in many instances of inconvenience and bad luck. Adventure education is one of the educational practices that actively utilize such hardships (i.e., adversity). In an adventure education program, a successful experience obtained by overcoming the mental stress felt in a maladaptive state brings about improvement of self (Okamura et al., 2005; Ihara et al., 2011; Imura, 1982). However, it was revealed that outdoor educators in this study think that [Definition of adversity] is necessary to protect participants from mental damage. This is because they believe that the adversity that participants confront in the natural world might drive them to a very difficult situation to continue activities. For example, mental damage could be the feeling of pain, boring, fear, compulsion, etc.

In recent times, many adventure education programs are being developed and practiced by bringing adventurous elements into a classroom and familiar places to avoid risk of direct experience in nature. Regarding this point, Iwanaga et al. (2007) and Konishi (2005) point out that packaged adventure education, which adopts recent experience learning methods, cannot result in the expected educational effect, because elements of adventure get diluted, since packaged adventure education programs are designed to avoid physical dangers. The outdoor educators in this study also believe that it would not be possible to experience nature dynamically through tasks that have been intentionally set by educators aiming to enhance the learning effect.

According to the National Myoko Youth Outdoor Learning Center (2006), a program design where participants feel a sense of accomplishment on completing a program is important in adventure education. Regarding the sense of accomplishment, the outdoor educators in this study believe that if the adversity experience ends with pain only, the participants may get a sense of accomplishment as the release from pain, but they would not get more pleasure. Regarding the experience of success, the outdoor educators think that it is possible to learn a lot from experiencing failure as well as success in intentionally set tasks. The teaching methods used in experiential learning are being introduced as teaching methods for outdoor education. Although the effect of introducing experiential learning theory in outdoor educational guidance is expected, as Hayashi and Iida (2002) pointed out, consideration should be given to taking advantage of the characteristics of outdoor education experience; for example, a program that enhances sensitivity. The outdoor educators of this study avoided setting artificial issues in [Program design] in order to directly experience nature as it is.

Outdoor educators in this program have been making efforts to realize direct experiences in [The influence of outdoor educators]. In addition, it was shown that the efforts influence the participants' [Rely on one's own sense or feeling]. In 
the category of [Rely on one's own sense or feeling], the concepts of control one's own senses and pro-active place, and the category [Miracles happen] are included. [Rely on one's own sense or feeling] means not moving with someone else when danger is approaching, but being able to sense and respond to danger using one's own senses and judgment. For that, it is important to control one's own senses. By getting more experience, [Ability to react to the nature] will be enhanced. If [Ability to react to the nature] becomes better, it would be possible to go deeper into nature more often. If so, the place would become pro-active place and the possibilities for the participants' experiences would be expanded further, and [Miracles happen]. According to Okamura et al. (2005), in outdoor educational situations, it is important not only to help participants overcome difficult challenges in a short period of time, but also to make them choose and participate subjectively in the long term to improve motivation. The results of the present study suggested that [The influence of outdoor educators] and their accumulated experience urge participants to [Rely on ones' own sense or feeling].

Self-growth is the confidence one gains after overcoming difficult situations and confronting unpleasant emotions. For this, it is essential to have the motivation to accomplish and make the effort to overcome (Kajita, 1998; Tanii et al., 2001; Hayami, 2008). From this fact, the effectiveness of the process-that Sense of achievement from a successful experience of overcoming [Adversity] becomes Self-confidence, and [Self-growth] is achieved-was supported. On the other hand, Sense of achievement while overcoming adversity influences [Flow] (Fun and Concentration); furthermore, this [Flow] should be the driving force to move [Mastery] and [Motivation]. The results of the study also suggested the possibility of promoting [Self-growth]. Csikszentmihalyi proposed the Flow Theory as a new model of endogenous motivation in 1975, and defined "flow" as "a comprehensive sense that people perceive when fully immersed in one act entirely" (Csikszentmihalyi, 1979). It is said that the Flow has a "cushioning role against adversity" (Imamura \& Asakawa, 2003). The results of the present study categorize the positive emotions of Overcoming fear, So fun we forget the fatigue, Scary but fun under the category of "Adversity". In addition, the participants gained a Sense of achievement while overcoming adversity. The Results also show that the psychological state at that time is [Flow]. This suggests that participants experience [Flow] when they are overcoming [Adversity].

Csikszentmihalyi (1996) says, "When choosing goals and projecting themselves to the limit of attention concentration, everything we do is fun. And once you enjoy this pleasure we will double our efforts to taste that pleasure again. This is the way the self grows". Thus, [Flow] must affect [Self-growth].

According to Daniel (2010), "mastery is the desire to make something valuable" and "Flow is an essential element for mastery". This suggests a strong relationship between [Flow] and [Mastery]. Further, according to Ishida (2010), Flow is closely related to endogenous motivation. Positive emotions, such as pleasure, are fed back into the improvement of endogenous motivation (Sakurai, 1997). From this, we suggest that [Flow] influences [Motivation]; therefore, [Flow] ought to be the driving force to continuously improve [Mastery] and increase [Motiva- 
tion].

According to Lala (2010), Flow represents more accurately what adventure educators need to do. Our results, too, indicate that the Flow Theory is an effective teaching tool for outdoor educators.

\section{Limitations of the Present Study}

The limitations of this research are as follows. Although we could study only a small sample in detail, it is impossible to generalize the results, because the outdoor educators' tendencies and actions in outdoor activities cannot be generalized. In addition, this research was conducted from the viewpoint of outdoor educators, which is multi-faceted, and it has not yet been comprehensively studied. Further, the structure of the Flow Model is limited, in that, the challenge and skill levels are dependent on the actors (Sako, 1998). In order for outdoor educators to be able to effectively utilize the Flow Theory as a teaching tool, it is necessary to consider such limitations.

\section{Conclusion}

The influence of outdoor educators on participants at BKACP was assessed to answer our research question. We discovered that skilled outdoor educators who know the rules of nature well and let participants rely on their senses and experience adversity prompt self-growth among the participants. It is especially important that there is freedom within the program and that adversity is defined for the participants to get a sense of achievement on overcoming the adversity. This is known as the Flow Theory, and is what ultimately promotes self-growth. We then explored the possibility of using Flow Theory, and discovered that in order to take advantage of Flow and realize the full value and potential of the program, the intervention of outdoor educators is essential.

Outdoor activities are valuable opportunities for children to gain value of endogenous remuneration. It is hoped that it will be widely acknowledged that abilities of children are drown out by intervention of outdoor educators and this significance will be shared.

For that, there are some proposals for various fields.

It is effective that outdoor educators regard Real nature active experience as important to use Power hidden within nature by keeping the balance of risk and freedom. Also children can improve their potential to react by cherishing their sense and feeling when they go into the nature.

The proposal for associations of outdoor education is to develop long-term program and provide deep experience with high degree of freedom in the nature world. By cooperating with the association, school should establish a structure which leads children to unusual nature experience from daily nature experience.

For researchers, it is recommendable to focus on the sense of achievement while overcoming adversity and the effect as a learning tool of a flow, which is positive emotion. 


\section{References}

Csikszentmihalyi, M. (1979). Beyond Boredom and Anxiety (H. Imamura Trans., p. 66). Kyoto: Shisakusha.

Csikszentmihalyi, M. (1996). Flow (H. Imamura Trans., p. 53). Kyoto: Sekaishisosha.

Daniel, H. P. (2010). Drive (K, Omae Trans., pp. 160-173). Tokyo: Kodansha.

Endo, H., Aoyagi, K., \& Oka, K. (2015). Development and Practice of Buddy Kids Adventure Challenge Program. Journal of Japan Society of Sports Industry, 2, 185- 199. https://doi.org/10.5997/sposun.25.2_185

Guest, G., Bunce, A., \& Johnson, L. (2006) How Many Interviews Are Enough? An Experiment with Date Saturation and Variability. Field Methods, 1, 59-82. https://doi.org/10.1177/1525822X05279903

Habata, M., \& Suzuki, M. (2010). The Nature of Child Learning. Bulletin Education Development Kagawa University, 20, 45-57.

Hayami, T. (2008). Gakushuiyoku no hattatsu (Increase Learning Motivation). Jido shinri, 10, 2-10. (In Japanese)

Hayashi, A., \& Iida, M. (2002). Instruction Methods in Outdoor Education Regarding Experiential Learning in the United States. Japan Outdoor Education Journal, 2, 11-20.

Hijikata, K. (2008). Analysis of the Personal Attitude Construct toward Instructions Provided at an Organized Camp for Children. Japan Outdoor Education Journal, 1, 13-26.

Hijikata, K. (2013). PAC Analysis of Significance about Nature-Based Experiential Activities: A Case Study of Leaders Who Had Abundant Experience. Japan Outdoor Education Journal, 2, 29-44. (In Japanese)

Ihara, K., \& Kajitani, K. (2011). The Influence of Elementary School Student's Adventure Education Program on Self-Efficacy. In Proceedings from the 14th Conference of Japan Outdoor Education Society Program Summary Abstract Book (pp. 26-27).

Imamura, H., \& Asakawa, K. (2003). Furoriron no tenkai [Deployment of flow theory] (p. 36). Kyoto: Sekaishisosha. (In Japanese)

Imura, H. (1982). The Influence of Adventure Camp on the Self-Concept and State- Anxiety of $7^{\text {th }}$ to $10^{\text {th }}$ Graders. Bulletin of Institute Health \& Sport Sciences, the University of Tsukuba, 5, 59-72.

Ishida, J. (2010). Significance and Challenges of "Flow Theory" as Intrinsic Motivation Theory. University of Hyogo, 45, 39-47.

Iwanaga, S., Kashiwagi, T., Fujioka, Y., Shibayama, A., \& Hashimoto, Y. (2007). Practices and Problem of the Project Adventure Program in Miyagi Prefecture. Naruto University of Education, 22, 37-50.

Kajita, E. (1998). Jikoishiki no shinrigaku (Psychology of Self-Consciousness) (2nd ed.). Tokyo: University of Tokyo Press. (In Japanese)

Kinoshita, Y. (2010). Modified of Grounded Theory Approach (pp. 89-91). Tokyo: Koubundo. (In Japanese)

Konishi, K. (2005). About Adventure Counseling and Adventure Education. Tezukayama University, 1, 9-25.

Lala, F. (2010). Adventure Education \& Csikszentmihalyi Flow Theory (p. 12). UMI.

Ministry of Education, Culture, Sports, Science and Technology-Japan (1996). Nijuisseiki wo tenboushita wagakunino kyouikunoarikatanitsuite (daiichijitoshin) [About the Way of the Japan's Education in Japan Viewing in the 21st Century (Primary Report)]. http://www.mext.go.jp/b_menu/shingi/old_chukyo/old_chukyo_index/toushin/130957 $\underline{9 . h t m}$ 
Ministry of Education, Culture, Sports, Science and Technology-Japan (2013). Jidaiwoninau jiritsushita seishonennnoikuseinimukete (toshin) [Towards the Development of Autonomous Youth Who Will Be Responsible for the Next Generation (Report)]. http://www.mext.go.jp/b_menu/shingi/chukyo/chukyo0/toushin/07020115.htm

National Institution for Youth Education (2006). A Survey on Actual Conditions on Young People's Nature Experience Activities etc. http://www.niye.go.jp/kenkyu_houkoku/contents/detail/i/12

National Institution for Youth Education (2010). Survey of Experiential Activities and Independence of Youth. http://www.niye.go.jp/kenkyu_houkoku/contents/detail/i/61/

National Institution for Youth Education (2011). Survey of Experiential Activities and Independence of Youth. http://www.niye.go.jp/kenkyu_houkoku/contents/detail/i/61/

National Myoko Youth Outdoor Learning Center (2006). Open the Door, National Myoko Youth Outdoor Learning Center (p. 28). Nigata.

Noguchi, K., \& Murayama, M. (1995). A Study on Role of Leaders in Outdoor Activities. Keio University, 1, 49-56.

Okamura, T., Araki, E., \& Kasanaga, E. (2005). The Effects of Physical Education Class Applying an Experiential Learning Method on Intrinsic Motivation of Students. Nara University of Education, 1, 93-10.

Onno, F. (2012). Junior Programs That Take Advantage of the Sea in the US West Coast. In Proceedings from the 15th Annual Meeting of Japan Outdoor Education Association (pp. 48-49).

Research and Collaborators Meeting and Report on Promotion of Outdoor Education for Young People (1996). Enhancement of Outdoor Education for Young People. http://www.mext.go.jp/b_menu/shingi/chousa/sports/003/toushin/960701.htm

Sako, T. (1998). Geido ni okeru furo taiken (Flow Experience in Art Gallery) (pp. 17-18). Hiroshima: Keisuisha. (In Japanese)

Sakurai, S. (1997). Gakushuiyoku no shinrigaku (Psychology of Motivation to Learn) (p. 22). Tokyo: Seishinsha. (In Japanese)

Tanii, J., \& Fujiwara, E. (2001). Evaluation Scale of Nature-Experience Programs for Elementary and Lower-Secondary School Children. Japan Outdoor Education Journal, 1, $39-47$.

\section{Submit or recommend next manuscript to SCIRP and we will provide best} service for you:

Accepting pre-submission inquiries through Email, Facebook, LinkedIn, Twitter, etc.

A wide selection of journals (inclusive of 9 subjects, more than 200 journals)

Providing 24-hour high-quality service

User-friendly online submission system

Fair and swift peer-review system

Efficient typesetting and proofreading procedure

Display of the result of downloads and visits, as well as the number of cited articles

Maximum dissemination of your research work

Submit your manuscript at: http://papersubmission.scirp.org/

Or contact ape@scirp.org 